\title{
Selection of optimal chelator improves the contrast of GRPR imaging using bombesin analogue RM26
}

\author{
BOGDAN MITRAN $^{1 *}$, ZOHREH VARASTEH $^{1 *}$, RAM KUMAR SELVARAJU $^{1}$, GUNNAR LINDEBERG $^{2}$, \\ JENS SÖRENSEN ${ }^{4}$, MATS LARHED ${ }^{5}$, VLADIMIR TOLMACHEV ${ }^{3}$, \\ ULRIKA ROSENSTRÖM $^{2}$ and ANNA ORLOVA ${ }^{1}$
}

\author{
${ }^{1}$ Division of Molecular Imaging, Department of Medicinal Chemistry, Faculty of Pharmacy; ${ }^{2}$ Organic Pharmaceutical \\ Chemistry, Department of Medicinal Chemistry, Faculty of Pharmacy, Uppsala University; ${ }^{3}$ Department of Immunology, \\ Genetics and Pathology, Faculty of Medicine, Uppsala University; ${ }^{4}$ Department of Medical Sciences, Clinical Physiology, \\ Uppsala University Hospital; ${ }^{5}$ Science for Life Laboratory, Department of \\ Medicinal Chemistry, Uppsala Biomedical Center, Uppsala University, Uppsala, Sweden
}

Received December 17, 2015; Accepted January 27, 2016

DOI: 10.3892/ijo.2016.3429

\begin{abstract}
Bombesin (BN) analogs bind with high affinity to gastrin-releasing peptide receptors (GRPRs) that are upregulated in prostate cancer and can be used for the visualization of prostate cancer. The aim of this study was to investigate the influence of radionuclide-chelator complexes on the biodistribution pattern of the ${ }^{111}$ In-labeled bombesin antagonist $\mathrm{PEG}_{2}$-D-Phe-Gln-Trp-Ala-Val-Gly-His-StaLeu-NH $\mathrm{NH}_{2}\left(\mathrm{PEG}_{2}-\mathrm{RM} 26\right)$ and to identify an optimal construct for SPECT imaging. A series of RM26 analogs N-terminally conjugated with NOTA, NODAGA, DOTA and DOTAGA via a $\mathrm{PEG}_{2}$ spacer were radiolabeled with ${ }^{111}$ In and evaluated both in vitro and in vivo. The conjugates were successfully labeled with ${ }^{111}$ In with $100 \%$ purity and retained binding specificity to GRPR and high stability. The cellular processing of all compounds was characterized by slow internalization. The $\mathrm{IC}_{50}$ values were in the low nanomolar range, with lower $\mathrm{IC}_{50}$ values for positively charged ${ }^{\text {nat } I n-N O T A-P E G}{ }_{2}-R_{2} 26(2.6 \pm 0.1 \mathrm{nM})$ and higher values for negatively charged ${ }^{\text {nat }}$ In-DOTAGA-PEG ${ }_{2}-$ RM26 (4.8 $\pm 0.5 \mathrm{nM})$. The kinetic binding studies showed $\mathrm{K}_{\mathrm{D}}$ values in the picomolar range that followed the same pattern as the $\mathrm{IC}_{50}$ data. The biodistribution of all compounds was studied in BALB/c nu/nu mice bearing PC-3 prostate cancer xenografts. Tumor targeting and biodistribution studies displayed
\end{abstract}

Correspondence to: Dr Ulrika Rosenström, Organic Pharmaceutical Chemistry, Department of Medicinal Chemistry, Faculty of Pharmacy, Uppsala University, Box 574, 75123 Uppsala, Sweden E-mail: ulrika.rosenstrom@orgfarm.uu.se

*Contributed equally

Key words: RM26, gastrin-releasing peptide receptor, bombesin antagonist analog, SPECT, chelators, NOTA, DOTA, NODAGA, DOTAGA rapid clearance of radioactivity from the blood and normal organs via kidney excretion. All conjugates showed similar uptake in tumors at $4 \mathrm{~h}$ p.i. The radioactivity accumulation in GRPR-expressing organs was significantly lower for DOTAand DOTAGA-containing constructs compared to those containing NOTA and NODAGA. ${ }^{111}$ In-NOTA-PEG $2-$ RM26 $_{2}$ with a positively charged complex showed the highest initial uptake and the slowest clearance of radioactivity from the liver. At 4 h p.i., DOTA- and DOTAGA-coupled analogs showed significantly higher tumor-to-organ ratios compared to NOTA- and NODAGA-containing variants. The NODAGA conjugate demonstrated the best retention of radioactivity in tumors, and, at $24 \mathrm{~h}$ p.i., had the highest contrast to blood, muscle and bones.

\section{Introduction}

Bombesin analogs, which show significant potential in the diagnosis and therapy of prostate cancer, have been widely investigated in recent years. The attractiveness of these peptides is determined by their ability to bind selectively and avidly to gastrin-releasing peptide receptors (GRPRs), which are ectopically expressed in several tumors, including prostate and breast cancer (1). Imaging of GRPR expression in prostate cancer using high-affinity radiolabeled bombesin analogs could therefore complement the current prostate-specific antigen (PSA)-based screening methods, which have limited standalone diagnostic specificity and can generate false positive and false negative results (2). This type of imaging could also provide an answer to the discrepancy between the histological prevalence and clinical disease encountered in biopsies (3). Moreover, it could allow preoperative assessment of lymph node involvement and other metastases, which are crucial preconditions for adequate staging and treatment selection (4). However, the detection of subcentimeter metastases is challenging and requires imaging solutions that are characterized by high sensitivity (5). 
The potential benefit of radionuclide molecular imaging using peptide-based targeting vectors is supported by the success reported for somatostatin analogs, which also paved the way for the design and development of several bombesin derivatives in the last decade. While the initial consensus was that internalization of the receptor-ligand complex is a decisive precondition for optimal imaging and therapy (6), the superior results obtained using somatostatin antagonists (7) led to a paradigm shift in bombesin analog development, from agonists to antagonists. The study by Cescato and co-workers showed that bombesin-based antagonists had superior tumor targeting and pharmacokinetic characteristics compared to agonists without eliciting a physiological response (8).

Recently, we have investigated a high-affinity antagonistic analog of bombesin [RM26, (D-Phe6, Sta13, Leu14)bombesin(6-14)] conjugated to a 1,4,7-triazacyclononane-N, N',N"-triacetic acid (NOTA) chelator via a diethylene glycol $\left(\mathrm{PEG}_{2}\right)$ spacer (NOTA-PEG $\left.{ }_{2}-\mathrm{RM} 26\right)$. This construct was labeled with ${ }^{68} \mathrm{Ga},{ }^{111} \mathrm{In}$ and $\mathrm{Al}^{18} \mathrm{~F}$ and showed favorable pharmacokinetic properties $(9,10)$. The high affinity to GRPR $\left(\mathrm{K}_{\mathrm{D}}\right.$ in the picomolar range) suggested that no further modifications of the peptide sequence are required (9). Nonetheless, several other parameters known to influence the targeting and biodistribution properties of radiopeptides could be employed to obtain higher sensitivity and specificity (11). Such parameters include overall and local distribution of charge and lipophilic patches and can be tuned by modifications to the spacers, chelating moieties and radionuclides.

Therefore, in a further attempt to optimize the biodistribution profile for possible clinical use, several modifications in the length of spacers and different chelating agents have been explored. The effects of the length of PEG spacers as hydrophilicity modifiers (NOTA-PEG ${ }_{n}-R^{2} 26$, $n=2,3,4,6$ ) were shown to be minor (12). However, the use of different macrocyclic chelators for the labeling of RM26 with ${ }^{68} \mathrm{Ga}$ had a profound influence on the biodistribution profile of bombesin analogs, appreciably altering the blood clearance, tumor uptake and kidney retention of radioactivity (13). In this regard, the constructs containing the triaza chelators NOTA and 1,4,7-triazacyclononane,1-glutaric acid-4,7-acetic acid (NODAGA), namely ${ }^{68} \mathrm{Ga}-\mathrm{NOTA}-\mathrm{PEG}_{2}-\mathrm{RM} 26$ and ${ }^{68} \mathrm{Ga}-\mathrm{NODAGA}-\mathrm{PEG}_{2}-\mathrm{RM} 26$ provided better imaging properties (higher tumor-to-organ ratios) compared to 1,4,7,10-tetraazacyclododecane-1,4,7,10-tetraacetic acid (DOTA) and 1,4,7,10-tetraazacyclododecane,1-(glutaric acid)4,7,10-triacetic acid (DOTAGA) coupled analogs. The higher tumor uptake and faster clearance from blood and healthy tissues indicated that NOTA is the superior chelator for ${ }^{68} \mathrm{Ga}$ labeling of RM26 (NOTA > NODAGA > DOTA > DOTAGA) for imaging of prostate cancer using positron emission tomography (PET) (13).

To date, despite its value as a high-end diagnostic tool, PET imaging is limited by the large infrastructure required for the production of $\beta^{+}$-emitting radioisotopes and the higher cost of imaging equipment, making PET an expensive technology (14). Single-photon emission computed tomography (SPECT) cameras, on the other hand, are more widely available, and there is a broader array of available and less-expensive SPECT radiotracers compared to PET tracers.
Moreover, SPECT radionuclides have a longer half-life, which allows for imaging at later time points when better contrast can be achieved. Additionally, SPECT radionuclides can be transported to distant hospitals and imaging centers. One commonly used SPECT radionuclide in clinical context is ${ }^{111} \mathrm{In}$ (2.8 days half-life).

Different radionuclides have also been known to impact the behavior of radiopharmaceuticals $(15,16)$. It is increasingly evident that the influence of radionuclides is intimately connected to the chelator moiety. Therefore, matching the isotopes and chelators could substantially improve the pharmacokinetic properties of radiotracers (17). A good match depends on a multitude of factors, including the coordination number of the metal ion, chelator denticity, radionuclidechelator complex geometry, oxidation state of the metal ion, and the rate of complex formation and dissociation (18).

The aim of the current study was to evaluate the influence of the radionuclide-chelator complex on the biodistribution and targeting properties of ${ }^{111}$ In-labeled bombesin antagonist RM26 and to identify an optimal construct for SPECT imaging of GRPR expression. For this purpose, four different constructs containing NOTA, NODAGA, DOTA and DOTAGA macrocyclic chelators [further denoted as $\mathrm{X}-\mathrm{PEG}_{2}-\mathrm{RM} 26, \mathrm{X}=\mathrm{NOTA}$, NODAGA, DOTA, DOTAGA (Fig. 1)] were radiolabeled with ${ }^{111}$ In and evaluated in vitro and in vivo.

\section{Materials and methods}

Peptide synthesis. X-PEG2-RM26 (RM26= [D-Phe6, Sta13, Leu14]Bombesin[6-14], X= NOTA, DOTA, NODAGA and DOTAGA) were synthesized by manual solid-phase peptide synthesis (SPPS) using standard Fmoc/t-Bu conditions, as previously described $(9,13)$. The identity was confirmed by HPLC/MS using a Kinetex $2.6 \mu \mathrm{m} \mathrm{C18} \mathrm{(50x3.0} \mathrm{mm)} \mathrm{column}$ and a $2.5-\mathrm{min}, 5-60 \%$ acetonitrile/water $(0.05 \%$ formic acid) gradient. Purity was determined by UV-HPLC $(220 \mathrm{~nm})$ and was $>96.5 \%$ for all conjugates (13).

Radiolabeling. All ${ }^{111}$ In labelings and quality controls were performed based on protocols developed and presented previously (9). Briefly, an aqueous solution of $10 \mathrm{nmol}(10 \mu \mathrm{l}$ in Milli-Q water) of X-PEG ${ }_{2}-\mathrm{RM}_{2} 6$ was buffered with $80 \mu \mathrm{l}$ (0.2 M, pH 5.5) of ammonium acetate (Merck). The buffers for ${ }^{111}$ In labeling were purified from metal contamination using Chelex 100 resin (Bio-Rad Laboratories). After the addition of $60 \mathrm{MBq}(80-150 \mu 1$ in $0.05 \mathrm{M}$ hydrochloric acid) of ${ }^{111}$ In (Covidien), the reaction mixture was incubated for $10 \mathrm{~min}$ at $90^{\circ} \mathrm{C}$.

The yield, radiochemical purity and in vitro stability studies of ${ }^{111}$ In-X-PEG 2 -RM26 were analyzed using instant thin-layer chromatography (ITLC) strips (150-771 Dark Green, Tec-Control Chromatography strips from Biodex Medical Systems). Citric acid (0.2 M, pH 2.0) was used as the running buffer. In this system, free indium and its complexes migrate with the solvent front $(\mathrm{R} f=1.0)$, while peptides remain at the origin $(\mathrm{R} f=0.0)$. The system was previously cross-validated using radioHPLC and radioSDS-PAGE (sodium dodecyl sulfate-polyacrylamide gel electrophoresis) $(9,10)$. To test the labeling stability, ${ }^{111}$ In-X-PEG - -RM26 was incubated for $1 \mathrm{~h}$ at room temperature in the presence of 1000 -fold molar excess 


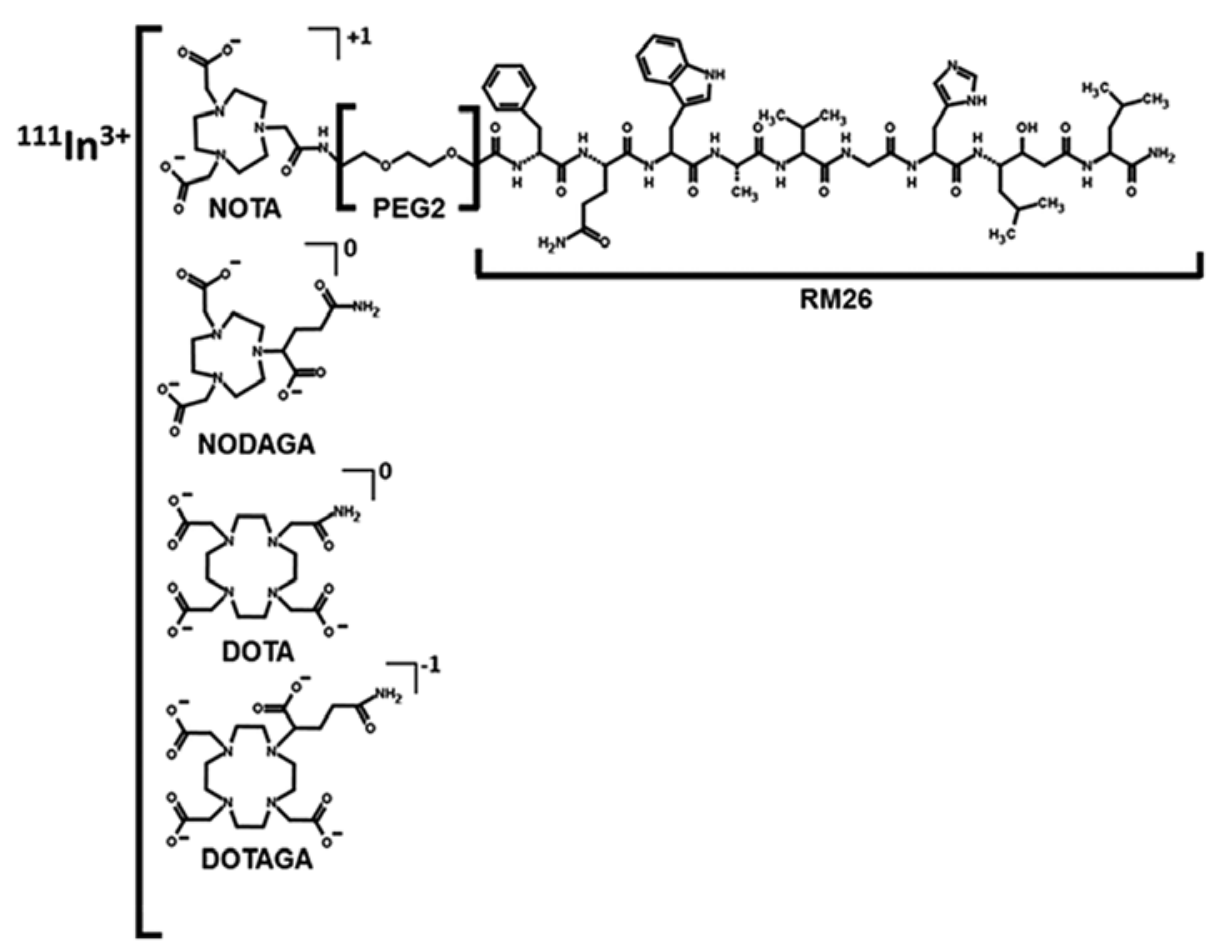

Figure 1. Schematic overview of the structures of four different chelators: NOTA, NODAGA, DOTA and DOTAGA, coupled to RM26 peptide via a PEG ${ }_{2}$ spacer.

of EDTA disodium salt (Sigma). The samples were analyzed by ITLC.

Before in vivo studies, the reaction mixtures of ${ }^{111} \mathrm{In}-\mathrm{X}$ $\mathrm{PEG}_{2}-\mathrm{RM} 26$ were additionally purified using solid phase extraction. Briefly, the reaction mixtures were diluted with $3 \mathrm{ml}$ of deionized water and passed through a $1 \mathrm{ml}$ Oasis HLB cartridge (Waters). The cartridge was then washed with $5 \mathrm{ml}$ of deionized water. The radiolabeled product was eluted with $1 \mathrm{ml}$ of 1:1 EtOH/water.

In vitro studies. GRPR-expressing PC-3 human prostate cancer cells (ATCC) were cultured in RPMI media complemented with $10 \%$ fetal calf serum, $2 \mathrm{mM}$ L-glutamine and PEST (penicillin $100 \mathrm{IU} / \mathrm{ml}$ ) (all from Biochrom AG). The cells were detached using trypsin-EDTA solution (0.05\% trypsin, $0.02 \%$ EDTA in buffer; Biochrom AG). All experiments were performed in triplicate and $0.7 \times 10^{6}$ cells/dish were seeded two days before the experiment.

For the in vitro binding specificity study, PC-3 cells were incubated with $1 \mathrm{nM}{ }^{111} \mathrm{In}-\mathrm{X}-\mathrm{PEG}_{2}-\mathrm{RM} 26$ solutions for $1 \mathrm{~h}$ at $37^{\circ} \mathrm{C}$. One set of dishes in each experiment was preincubated with 100-fold excess of unlabeled peptide, added 10 min before the addition of the radiolabeled compounds. After being washed once with serum-free media, cells were treated with $0.5 \mathrm{ml}$ trypsin solution. Cell-associated radioactivity was measured in an automated gamma-counter (3-inch $\mathrm{NaI}(\mathrm{Tl})$ detector, 1480 Wizard, Wallac Oy) and presented as percentage from added radioactivity.

Cellular processing was performed on PC-3 cells, which were incubated with $2 \mathrm{nM}$ of ${ }^{111} \mathrm{In}-\mathrm{X}-\mathrm{PEG}_{2}-\mathrm{RM} 26$ at $37^{\circ} \mathrm{C}$. At predetermined time points $(1,2,4,8$, and $24 \mathrm{~h}$ after the start of incubation), the incubation medium was discarded, the cells were washed and the membrane-bound and internalized radioactivity was collected using the acid wash method previously described (9).

The half-inhibitory concentration $\left(\mathrm{IC}_{50}\right)$ was estimated for ${ }^{\text {nat } I n-l o a d e d ~ m e t a l l o p e p t i d e s ~ b y ~ c o m p l e t e ~ d i s p l a c e m e n t ~}$ experiments using the universal $\mathrm{BN}$ radioligand ${ }^{125} \mathrm{I}-\mathrm{Tyr}^{4}-\mathrm{BBN}$ (Perkin Elmer) and increasing concentrations of the metallopeptides (0-1000 nM). Cell monolayers were incubated with nat In-X-PEG $-\mathrm{PM}_{2} 6$ in the presence of $0.1 \mathrm{pmol}$ $(\sim 200,000 \mathrm{cpm}){ }^{125} \mathrm{I}-\mathrm{Tyr}^{4}-\mathrm{BBN}$ for $5 \mathrm{~h}$ at $4^{\circ} \mathrm{C}$. After incubation, the cells were harvested, and cell-associated radioactivity was determined as described above. The half-maximal inhibitory concentration values were calculated by fitting the data by nonlinear regression using GraphPad Prism software (GraphPad Software Inc.).

The kinetic binding studies were performed using LigandTracer Yellow Instruments (Ridgeview Instruments AB) at room temperature, as previously described (19). Briefly, a Petri dish (Nunclon, diameter $100 \mathrm{~mm}$, containing $3 \mathrm{ml}$ culture medium) with PC-3 cells was attached to the rotating table of the instrument. After a 10-min baseline run, ${ }^{111} \mathrm{In}-\mathrm{X}-\mathrm{PEG}_{2}-\mathrm{RM} 26$ was added to the medium to obtain a ligand concentration of $0.3 \mathrm{nM}$, and the uptake curve was recorded for $200 \mathrm{~min}$. Thereafter, the ligand concentration was increased to $10 \mathrm{nM}$, and the uptake curve was recorded for another $150 \mathrm{~min}$. Then, ${ }^{111} \mathrm{In}-\mathrm{X}-\mathrm{PEG}_{2}-\mathrm{RM} 26$-containing medium was aspirated, $3 \mathrm{ml}$ of fresh medium were added, and the dissociation curve was followed overnight. Interaction analysis and calculation of the equilibrium dissociation constant $\left(\mathrm{K}_{\mathrm{D}}\right)$ were performed with TracerDrawer software (Ridgeview Instruments $A B$ ).

In vivo studies. All animal experiments were planned and performed according to the national legislation on the protection of laboratory animals, and the study plans were approved 
Table I. Labeling and stability of ${ }^{111} \mathrm{In}-\mathrm{X}-\mathrm{PEG}_{2}-\mathrm{RM} 26$ (X=NOTA, NODAGA, DOTA and DOTAGA). ${ }^{\mathrm{a}}$

\begin{tabular}{|c|c|c|c|c|}
\hline & NOTA & NODAGA & DOTA & DOTAGA \\
\hline Labeling yield for ${ }^{111} \mathrm{In}$ & $98.5 \pm 0.5$ & $99.6 \pm 0.2$ & $99.2 \pm 0.8$ & $97.6 \pm 2.3$ \\
\hline Purity after HLB & 100 & 100 & 100 & 100 \\
\hline Release in the presence of excess EDTA & $3.7 \pm 0.2$ & $6.2 \pm 0.3$ & $0.4 \pm 0.5$ & $2.4 \pm 3.3$ \\
\hline Release in PBS & $1.5 \pm 0.6$ & $1.7 \pm 0.1$ & 0 & $0.9 \pm 0.6$ \\
\hline
\end{tabular}

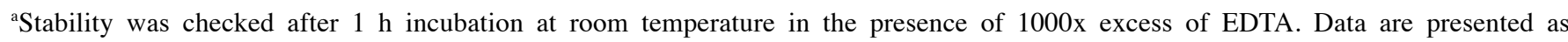
average \pm standard deviation.

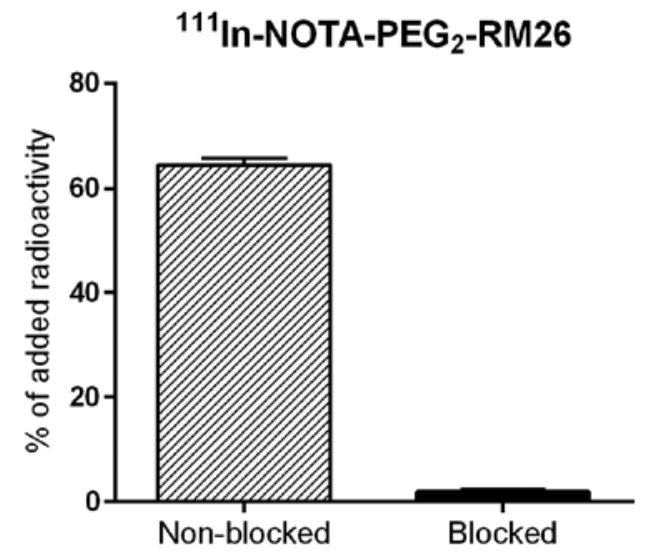

${ }^{111}$ In-DOTA-PEG 2 -RM26

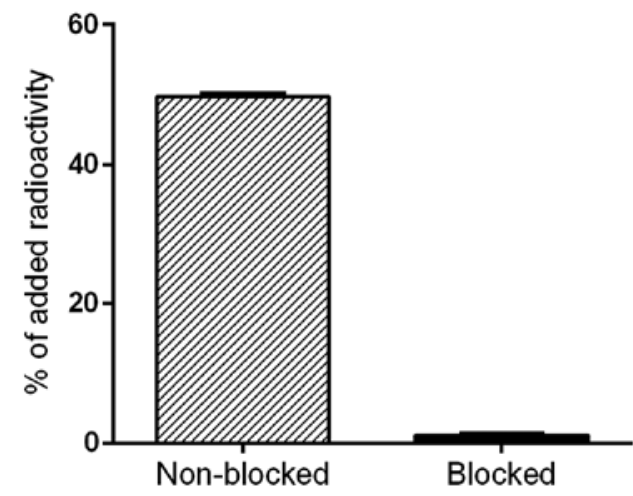

${ }^{111}$ In-NODAGA-PEG 2 -RM26

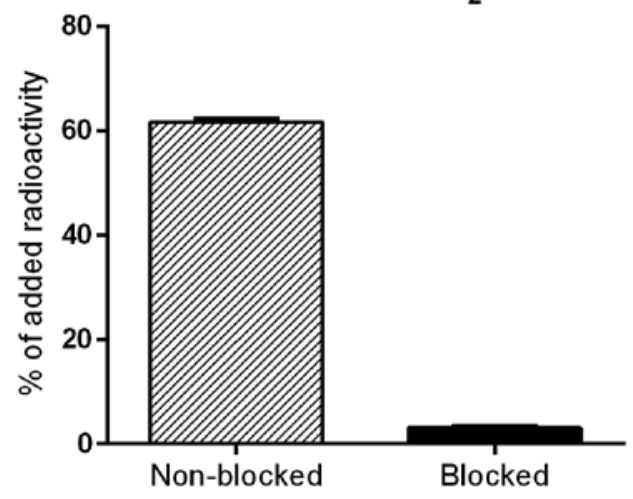

${ }^{111}$ In-DOTAGA-PEG 2 -RM26

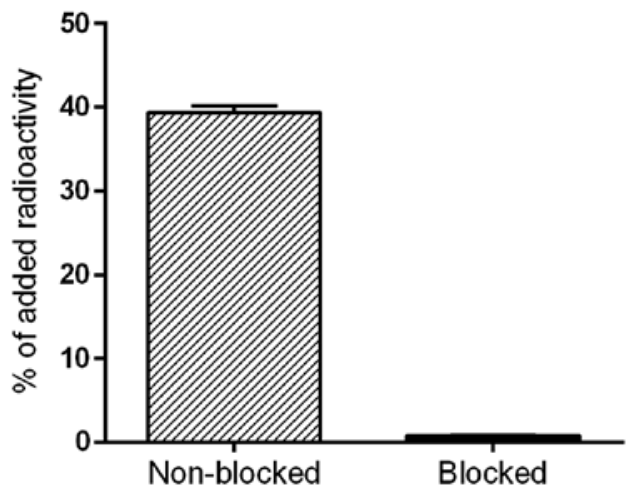

Figure 2. In vitro binding specificity of ${ }^{111} \mathrm{In}-\mathrm{X}-\mathrm{PEG}_{2}-\mathrm{RM} 26$ (X=NOTA, NODAGA, DOTA and DOTAGA) tested on PC-3 cells. Blocked dishes were pretreated with a 100-fold excess of non-labeled peptide $10 \mathrm{~min}$ prior to the addition of $1 \mathrm{nM}$ radiolabeled compounds. The cell-associated radioactivity is presented as a percentage of the total added radioactivity (mean values of three dishes $\pm \mathrm{SD}$ ).

by the local committee for animal research ethics. Groups of 4 mice per data point were used. The biodistribution and targeting to GRPRs of ${ }^{111} \mathrm{In}-\mathrm{X}-\mathrm{PEG}_{2}-\mathrm{RM} 26$ were evaluated in female BALB/c nu/nu mice (weight: $21 \pm 1 \mathrm{~g}$ ) bearing PC-3 xenografts $\left(10^{7}\right.$ cells/mouse, implanted 2 weeks before the experiment). The average tumor size was $0.32 \pm 0.17 \mathrm{~g}$ at the time of the experiment.

To study tumor targeting, mice bearing PC-3 xenografts were intravenously injected into the tail vein with $45 \mathrm{pmol}$ of ${ }^{111} \mathrm{In}-\mathrm{X}-\mathrm{PEG}_{2}-\mathrm{RM} 26(30 \mathrm{kBq}, 100 \mu \mathrm{l})$. The injected peptide dose was adjusted by dilution with non-labeled $\mathrm{X}-\mathrm{PEG}_{2}-\mathrm{RM} 26$. The mice were euthanized at 4 and $24 \mathrm{~h}$ post-injection (p.i.) by intraperitoneal injection of a KetalarRompun solution $(10 \mathrm{mg} / \mathrm{ml}$ Ketalar and $1 \mathrm{mg} / \mathrm{ml}$ Rompun; $20 \mu \mathrm{l}$ of solution per gram of body weight). Blood samples were collected by heart puncture. The organs of interest were collected and weighed, and their radioactivity content was measured in a gamma-counter. The organ uptake values were expressed as a percentage of injected dose per gram of tissue weight $(\% \mathrm{ID} / \mathrm{g})$.

Small animal SPECT/CT imaging. Whole body scans of the subjects, injected with ${ }^{111}$ In-X-PEG $2-R M 26$ (45 pmol, $300 \mathrm{kBq}$ ) were performed using the Triumph ${ }^{\mathrm{TM}}$ Trimodality 

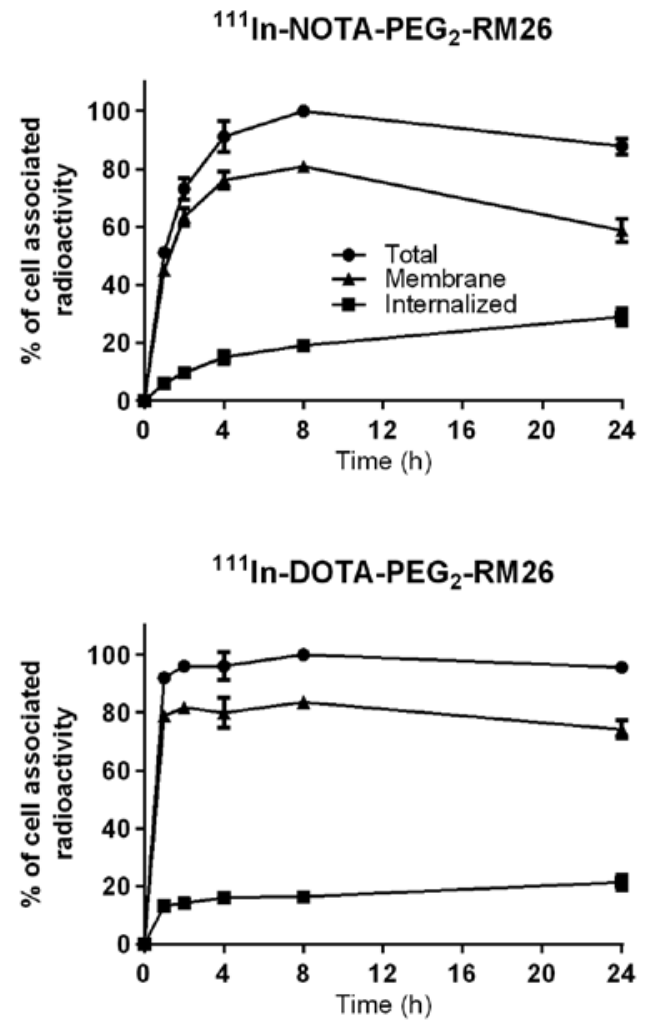
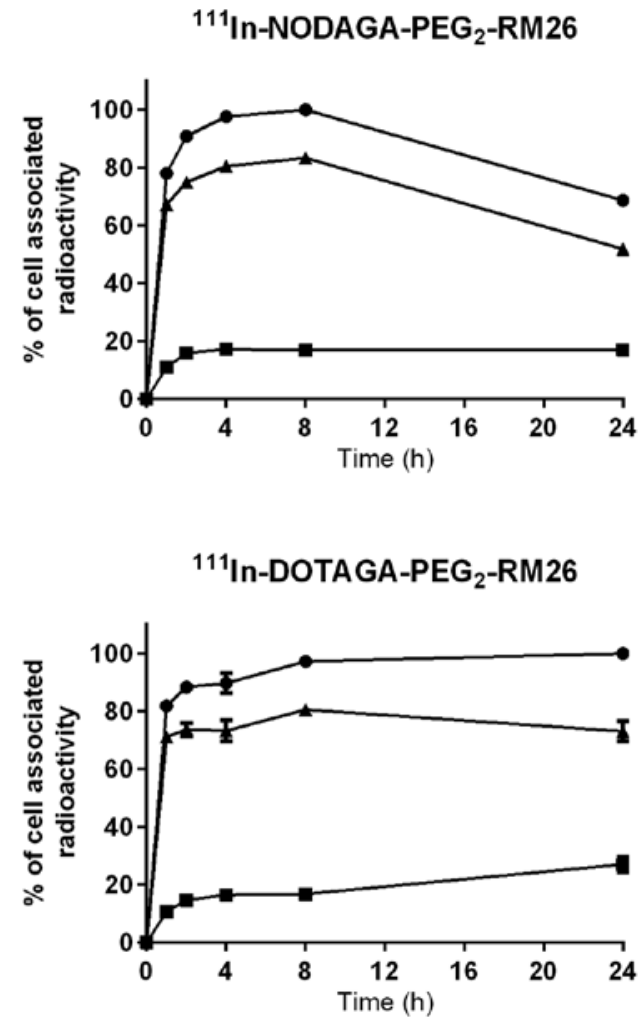

Figure 3. Cellular processing (internalized, membrane-bound and total radioactivity as a function of time after continuous incubation of PC-3 cells with 2 nM of ${ }^{111}$ In-X-PEG - RM26 where X=NOTA, NODAGA, DOTA and DOTAGA). Data are presented as the mean values of three dishes \pm SD. Not all error bars are visible due to the small standard deviations.

System (TriFoil Imaging, Inc., Northridge, CA, USA) at $4 \mathrm{~h}$ and $24 \mathrm{~h}$ p.i. The subjects were euthanized by $\mathrm{CO}_{2}$ asphyxiation immediately before being placed in the camera. A computed tomography (CT) acquisition was first carried out to position the body of the animal in the camera at the following parameters: field of view (FOV), $80 \mathrm{~mm}$; magnification, 1.48; one projection and 512 frames for $2.13 \mathrm{~min}$. Subsequently, SPECT acquisition was performed in same position with the following parameters: FOV, $8 \mathrm{~cm}$; 75A10 collimators (5 pinhole); acquisition energy window over $150-250 \mathrm{keV}$; 32 projections.

CT raw files were reconstructed by Filter Back Projection (FBP). SPECT raw data were reconstructed by FLEX SPECT software, which uses an ordered Subset Expectation Maximization (OSEM) iterative reconstruction algorithm. SPECT and CT data were fused and analyzed using PMOD v3.508 (PMOD Technologies Ltd., Zurich, Switzerland). Coronal SPECT-CT images of the scans were presented as maximum intensity projections (MIP) in RGB color scale to obtain a visual confirmation of the biodistribution results.

Statistics. Statistical analyses were performed by unpaired, two-tailed t-test using GraphPad Prism (version 4.00 for windows GraphPad Software, San Diego, CA, USA). P-values $<0.05$ were considered significant.

\section{Results}

Labeling chemistry. All constructs were successfully labeled with ${ }^{111} \mathrm{In}$, and the average yield was above $97 \%$ (Table I).
Therefore, no additional purification was required for in vitro studies. Stability was evaluated in the presence of both 1000-fold molar excess of EDTA and in PBS for $1 \mathrm{~h}$ at room temperature, and the subsequent ITLC analysis showed stable coupling of ${ }^{111} \mathrm{In}$ for all conjugates (Table I).

In vitro characterization. The results of binding specificity tests are presented in Fig. 2. Pre-saturation of receptors by adding a large molar excess of non-labeled peptide caused a significant $\left(\mathrm{p}<1.3 \times 10^{-7}\right)$ reduction in the radioactivity bound to GRPR-expressing PC-3 cells, demonstrating that the uptake was receptor mediated.

Data concerning cellular processing of ${ }^{111} \mathrm{In}-\mathrm{X}-\mathrm{PEG}_{2}-\mathrm{RM} 26$ by PC-3 cells are presented in Fig. 3. The rapid binding of all four conjugates to PC-3 cells was accompanied by slow internalization, reaching $33 \%$ of cell-associated radioactivity for ${ }^{111}$ In-NOTA$\mathrm{PEG}_{2}-\mathrm{RM} 26 ; 25 \%$ for ${ }^{111}$ In-NODAGA-PEG ${ }_{2}-\mathrm{RM}_{2} 6 ; 22 \%$ for ${ }^{111}$ In-DOTA-PEG 2 -RM26; and $27 \%$ for ${ }^{111}$ In-DOTAGA$\mathrm{PEG}_{2}-\mathrm{RM} 26$ after $24 \mathrm{~h}$ of incubation at $37^{\circ} \mathrm{C}$. The pattern of cell-associated radioactivity over time for ${ }^{111} \mathrm{In}$-NODAGA$\mathrm{PEG}_{2}-\mathrm{RM} 26$ differed from the patterns observed for the other conjugates, despite the fact they were tested simultaneously. Maximum cell- associated radioactivity was reached after $8 \mathrm{~h}$ of incubation for all conjugates. For ${ }^{111}$ In-NODAGA-PEG $2-$ RM26, the cell-associated radioactivity decreased by $30 \%$ from the maximum at $24 \mathrm{~h}$, while for the other conjugates it plateaued.

The half-maximal inhibitory concentration $\left(\mathrm{IC}_{50}\right)$ was determined for ${ }^{\text {nat } I n-l o a d e d ~ a n a l o g s ~ u s i n g ~}{ }^{125} \mathrm{I}-\mathrm{Tyr}^{4}-\mathrm{BBN}$ as a displacement radioligand (Table II and Fig. 4). All $\mathrm{IC}_{50}$ values were in the low nanomolar range. However, chelator-dependent 
Table II. Inhibition of ${ }^{125} \mathrm{I}_{-} \mathrm{Tyr}^{4}-\mathrm{BBN}$ binding to PC-3 cells with ${ }^{\text {nat } I n-X-P E G 2-R M 26 ~(X=N O T A, ~ N O D A G A, ~ D O T A ~ a n d ~ D O T A G A) . ~}$

\begin{tabular}{|c|c|c|c|c|}
\hline \multirow{2}{*}{$\begin{array}{l}{ }^{111} \mathrm{In}-\mathrm{X}-\mathrm{PEG}_{2^{-}} \\
\text {RM26 }\end{array}$} & \multirow{2}{*}{ 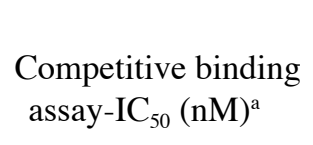 } & \multicolumn{3}{|c|}{ Real-time binding kinetics (LigandTracer) ${ }^{\mathrm{b}}$} \\
\hline & & $\mathrm{k}_{\mathrm{a}}\left(\mathrm{M}^{-1} \sec ^{-1}\right)$ & $\mathrm{k}_{\mathrm{d}}\left(\sec ^{-1}\right)$ & $\mathrm{K}_{\mathrm{D}}(\mathrm{nM})$ \\
\hline NOTA & $2.6 \pm 0.1$ & $(1.7 \pm 0.7) \times 10^{5}$ & $(3.1 \pm 0.6) \times 10^{-5}$ & $0.21 \pm 0.09$ \\
\hline DOTA & $2.8 \pm 0.2$ & $(1.1 \pm 0.2) \times 10^{5}$ & $(3.1 \pm 1.6) \times 10^{-5}$ & $0.37 \pm 0.08$ \\
\hline NODAGA & $3.7 \pm 0.2$ & $(0.4 \pm 0.1) \times 10^{5}$ & $(1.3 \pm 1.4) \times 10^{-5}$ & $0.36 \pm 0.11$ \\
\hline DOTAGA & $4.8 \pm 0.5$ & $(1.4 \pm 0.1) \times 10^{5}$ & $(6.1 \pm 1.4) \times 10^{-5}$ & $0.44 \pm 0.05$ \\
\hline
\end{tabular}

${ }^{\mathrm{a}}$ Data are presented as the mean values of three dishes $\pm \mathrm{SD} .{ }^{\mathrm{b}}$ Data are presented as average \pm standard deviation.

Table III. Biodistribution of ${ }^{111}$ In-X-PEG 2 -RM26 (X=NOTA, NODAGA, DOTA, DOTAGA) in PC-3-xenografted BALB/c nu/nu mice 4 and 24 h p.i.

\begin{tabular}{|c|c|c|c|c|c|c|c|c|}
\hline \multirow[b]{2}{*}{ Organ } & \multicolumn{2}{|c|}{ NOTA } & \multicolumn{2}{|c|}{ NODAGA } & \multicolumn{2}{|c|}{ DOTA } & \multicolumn{2}{|c|}{ DOTAGA } \\
\hline & 4 h p.i. & 24 h p.i. & 4 h p.i. & 24 h p.i. & 4 h p.i. & 24 h p.i. & 4 h p.i. & 24 h p.i. \\
\hline Blood & $0.0535 \pm 0.003^{\mathrm{a}, \mathrm{b}}$ & $0.008 \pm .002^{\mathrm{b}, \mathrm{c}}$ & $0.15 \pm 0.01^{\mathrm{c}}$ & $0.012 \pm 0.003^{b, c}$ & $0.13 \pm 0.02^{\mathrm{c}}$ & $0.023 \pm 0.004$ & $0.07 \pm 0.02$ & $0.025 \pm 0.008$ \\
\hline Lung & $0.20 \pm 0.04^{\mathrm{b}, \mathrm{c}}$ & $0.06 \pm 0.03$ & $0.18 \pm 0.03^{b, c}$ & $0.06 \pm 0.06$ & $0.08 \pm 0.01$ & $0.022 \pm 0.008$ & $0.08 \pm 0.02$ & $0.05 \pm 0.02$ \\
\hline Liver & $2.4 \pm 0.2^{\mathrm{a}, \mathrm{b}, \mathrm{c}}$ & $1.5 \pm 0.2^{\mathrm{a}, \mathrm{b}, \mathrm{c}}$ & $1.2 \pm 0.2^{\mathrm{c}}$ & $0.41 \pm 0.08$ & $1.0 \pm 0.3^{\mathrm{c}}$ & $0.30 \pm 0.08$ & $0.57 \pm 0.10$ & $0.4 \pm 0.1$ \\
\hline Spleen & $0.7 \pm 0.1^{\mathrm{b}}$ & $0.29 \pm 0.05^{\mathrm{c}}$ & $0.6 \pm 0.1^{\mathrm{b}}$ & $0.28 \pm 0.07^{\mathrm{c}}$ & $1.1 \pm 0.3$ & $0.4 \pm 0.1$ & $0.7 \pm 0.3$ & $0.6 \pm 0.1$ \\
\hline Pancreas & $2.2 \pm 0.2^{\mathrm{a}, \mathrm{b}, \mathrm{c}}$ & $0.076 \pm 0.009^{\mathrm{a}, \mathrm{b}, \mathrm{c}}$ & $16 \pm 2^{b, c}$ & $0.22 \pm 0.05^{\mathrm{b}, \mathrm{c}}$ & $0.19 \pm 0.0^{\mathrm{c}}$ & $0.02 \pm 0.01$ & $0.11 \pm 0.02$ & $0.021 \pm 0.004$ \\
\hline Stomach & $1.1 \pm 0.3^{\mathrm{b}, \mathrm{c}}$ & $0.09 \pm 0.03^{\mathrm{a}, \mathrm{b}, \mathrm{c}}$ & $2.0 \pm 0.7^{b, c}$ & $0.19 \pm 0.08^{\mathrm{b}, \mathrm{c}}$ & $0.15 \pm 0.0^{\mathrm{c}}$ & $0.03 \pm 0.01$ & $0.07 \pm 0.01$ & $0.02 \pm 0.01$ \\
\hline Intestines & $1.1 \pm 0.1^{\mathrm{a}, \mathrm{b}, \mathrm{c}}$ & $0.09 \pm 0.01^{\mathrm{b}, \mathrm{c}}$ & $2.9 \pm 0.6^{\mathrm{b}, \mathrm{c}}$ & $0.10 \pm 0.03^{\mathrm{b}, \mathrm{c}}$ & $0.06 \pm 0.02$ & $0.02 \pm 0.01$ & $0.06 \pm 0.01$ & $0.02 \pm 0.01$ \\
\hline Kidney & $3.6 \pm 0.3^{\mathrm{a}, \mathrm{b}, \mathrm{c}}$ & $1.3 \pm 0.3^{\mathrm{a}, \mathrm{b}}$ & $6.5 \pm 0.8^{b, c}$ & $2.6 \pm 0.4^{\mathrm{b}, \mathrm{c}}$ & $2.4 \pm 0.2^{\mathrm{c}}$ & $0.63 \pm 0.02^{\mathrm{c}}$ & $2.9 \pm 0.2$ & $1.7 \pm 0.3$ \\
\hline Tumor & $2.5 \pm 0.9$ & $1.7 \pm 0.5^{\mathrm{a}}$ & $3.6 \pm 0.8^{c}$ & $2.7 \pm 0.6^{b, c}$ & $3.4 \pm 0.6^{\mathrm{c}}$ & $1.27 \pm 0.2$ & $2.3 \pm 0.4$ & $1.4 \pm 0.3$ \\
\hline Muscle & $0.06 \pm 0.01^{\mathrm{b}, \mathrm{c}}$ & $0.020 \pm 0.005^{\mathrm{a}, \mathrm{b}, \mathrm{c}}$ & $0.05 \pm 0.02^{\mathrm{b}, \mathrm{c}}$ & $0.006 \pm 0.003$ & $0.016 \pm 0.003$ & $0.002 \pm 0.004$ & $0.012 \pm 0.005$ & $0.008 \pm 0.006$ \\
\hline Bone & $0.11 \pm 0.03^{b, c}$ & $0.07 \pm 0.02$ & $0.08 \pm 0.02^{\mathrm{c}}$ & $0.04 \pm 0.02$ & $0.05 \pm 0.03$ & $0.03 \pm 0.02$ & $0.03 \pm 0.01$ & $0.03 \pm 0.02$ \\
\hline Carcass $^{\mathrm{d}}$ & $4.4 \pm 0.2^{\mathrm{a}, \mathrm{b}, \mathrm{c}}$ & $0.9 \pm 0.3$ & $12.6 \pm 0.8^{\mathrm{b}, \mathrm{c}}$ & $0.65 \pm 0.06^{\mathrm{b}}$ & $1.81 \pm 0.4$ & $0.4 \pm 0.1$ & $1.5 \pm 0.5$ & $0.5 \pm 0.3$ \\
\hline
\end{tabular}

The organ uptake values are expressed as a percentage of injected dose per gram of tissue weight (\% ID/g) except for carcass, for which the values are expressed as a percentage of the injected dose per sample (\% ID). Significant difference $(\mathrm{P}<0.05)$ at the same time point: ${ }^{\mathrm{a} C o n j u g a t e}$

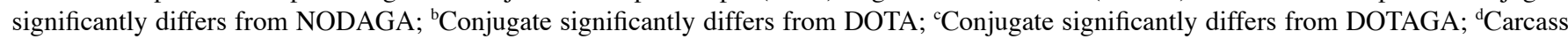
includes gastrointestinal tract with contents and the remaining animal carcass.

differences in affinity could be seen. The $\mathrm{IC}_{50}$ values of nat In$\mathrm{X}-\mathrm{PEG}_{2}-\mathrm{RM} 26$ were lower for positively charged NOTA $(2.6 \pm 0.1 \mathrm{nM})$, followed by neutral NODAGA and DOTA complexes (3.7 \pm 0.2 and $2.8 \pm 0.2 \mathrm{nM}$, respectively). The highest $\mathrm{IC}_{50}$ values (lowest affinity) were obtained for the negatively charged ${ }^{\text {nat In-DOTAGA-PEG }}{ }_{2}-\mathrm{RM}_{2} 6(4.8 \pm 0.5 \mathrm{nM})$.

The binding affinity of ${ }^{111}{ }^{1 n}-\mathrm{X}-\mathrm{PEG}_{2}-\mathrm{RM} 26$ to PC-3 cells was measured using LigandTracer Yellow instruments (Table II). The calculated $\mathrm{K}_{\mathrm{D}}$ values were in the subnanomolar range and had the same pattern as the $\mathrm{IC}_{50}$ values, i.e., the affinity of ${ }^{111}$ In-NOTA-PEG ${ }_{2}-\mathrm{RM}_{2} 6$ was the highest and the affinity of ${ }^{111}$ In-DOTAGA-PEG ${ }_{2}-\mathrm{RM}_{2} 6$ was the lowest. It should be noted that all values were in a very narrow range.

In vivo studies. Biodistribution of radiolabeled conjugates and comparison of their in vivo tumor targeting were performed in female BALB/c nu/nu mice bearing PC-3 xenografts 4 and
24 h p.-i.(Table III). Data obtained for ${ }^{111}$ In-NOTA-PEG $2-$ RM26 at $24 \mathrm{~h}$ p.i. were in good agreement with previously published results (9). All conjugates demonstrated rapid whole body and blood clearance via kidney excretion. The rapid blood clearance indicated good stability of radiolabeled compounds toward transchelation to blood proteins. All conjugates demonstrated rapid and nearly equal uptakes in tumors $4 \mathrm{~h}$ p.i. However, the radioactivity retention in tumors at $24 \mathrm{~h}$ p.i. differed. While the average radioactivity concentration decreased by $25-30 \%$ for the NOTA- and NODAGA-containing variants, it dropped by $40 \%$ for the DOTAGA conjugate and by $60 \%$ for the DOTA conjugate.

The pattern of radioactivity distribution in normal organs was different for the studied conjugates. The accumulated radioactivity in the liver and GRPR-expressing organs was significantly higher for ${ }^{111}$ In-NOTA-PEG 2 -RM26 and ${ }^{111}$ In-NODAGAPEG $_{2}-\mathrm{RM}_{26}$ compared to ${ }^{111}$ In-DOTA-PEG $2-\mathrm{RM}_{2} 6$ and 
Table IV. Tumor-to-normal-tissue ratios of ${ }^{111} \mathrm{In}-\mathrm{X}-\mathrm{PEG}_{2}-\mathrm{RM} 26$ (X=NOTA, NODAGA, DOTA and DOTAGA) in PC-3xenografted BALB/c nu/nu mice $4 \mathrm{~h}$ and $24 \mathrm{~h}$ p.i.

\begin{tabular}{|c|c|c|c|c|c|c|c|c|}
\hline \multirow[b]{2}{*}{ Organ } & \multicolumn{2}{|c|}{ NOTA } & \multicolumn{2}{|c|}{ NODAGA } & \multicolumn{2}{|c|}{ DOTA } & \multicolumn{2}{|c|}{ DOTAGA } \\
\hline & 4 h p.i. & 24 h p.i. & 4 h p.i. & 24 h p.i. & 4 h p.i. & 24 h p.i. & 4 h p.i. & 24 h p.i. \\
\hline Blood & $47 \pm 18$ & $196 \pm 20^{b, c}$ & $24 \pm 5$ & $253 \pm 93^{b, c}$ & $27 \pm 6$ & $56 \pm 14$ & $36 \pm 13$ & $58 \pm 17$ \\
\hline Lung & $13 \pm 6^{\mathrm{a}, \mathrm{b}, \mathrm{c}}$ & $29 \pm 9^{b}$ & $20 \pm 1^{\mathrm{b}, \mathrm{c}}$ & $82 \pm 49$ & $44 \pm 7^{c}$ & $64 \pm 18^{c}$ & $30 \pm 5$ & $33 \pm 14$ \\
\hline Liver & $1 \pm 0.4^{\mathrm{a}, \mathrm{b}, \mathrm{c}}$ & $1 \pm 0.2^{\mathrm{a}, \mathrm{b}, \mathrm{c}}$ & $3.1 \pm 0.4$ & $6.6 \pm 0.2^{c}$ & $4 \pm 1$ & $4 \pm 2$ & $4 \pm 1$ & $3.3 \pm 0.5$ \\
\hline Spleen & $4 \pm 1^{\mathrm{a}}$ & $6 \pm 1^{\mathrm{a}, \mathrm{c}}$ & $6 \pm 1^{\mathrm{b}}$ & $10 \pm 1^{\mathrm{b}, \mathrm{c}}$ & $3.1 \pm 0.6$ & $4 \pm 2$ & $4 \pm 2$ & $2.5 \pm 0.7$ \\
\hline Pancreas & $1.1 \pm 0.5^{\mathrm{a}, \mathrm{b}, \mathrm{c}}$ & $22 \pm 6^{\mathrm{a}, \mathrm{b}, \mathrm{c}}$ & $0.23 \pm 0.04^{b, c}$ & $12 \pm 2^{\mathrm{b}, \mathrm{c}}$ & $18 \pm 2$ & $55 \pm 17$ & $21 \pm 5$ & $69 \pm 13$ \\
\hline Stomach & $2.3 \pm 0.6^{\mathrm{b}, \mathrm{c}}$ & $20 \pm 4^{b, c}$ & $1.8 \pm 0.6^{\mathrm{b}, \mathrm{c}}$ & $16 \pm 6^{\mathrm{b}, \mathrm{c}}$ & $24 \pm 6^{c}$ & $39 \pm 7$ & $35 \pm 4$ & $106 \pm 64$ \\
\hline Small intestines & $2 \pm 1^{b, c}$ & $18 \pm 7^{\mathrm{b}, \mathrm{c}}$ & $1.3 \pm 0.4^{b, c}$ & $27 \pm 5$ & $62.63 \pm 22^{c}$ & $93 \pm 58$ & $37 \pm 5$ & $92 \pm 56$ \\
\hline Kidney & $0.7 \pm 0.2^{\mathrm{b}}$ & $1.3 \pm 0.3^{\mathrm{c}}$ & $0.6 \pm 0.1^{b, c}$ & $1.1 \pm 0.2^{\mathrm{b}}$ & $1.41 \pm 0.2^{\mathrm{c}}$ & $2.0 \pm 0.4^{\mathrm{c}}$ & $0.8 \pm 0.1$ & $0.8 \pm 0.2$ \\
\hline Muscle & $42 \pm 19^{\mathrm{b}, \mathrm{c}}$ & $83 \pm 30^{\mathrm{a}}$ & $86 \pm 34^{\mathrm{b}}$ & $646 \pm 408$ & $212 \pm 52$ & $284 \pm 126$ & $228 \pm 136$ & $277 \pm 252$ \\
\hline Bone & $23 \pm 6^{\mathrm{a}, \mathrm{b}, \mathrm{c}}$ & $27 \pm 8$ & $43 \pm 6^{c}$ & $104 \pm 92$ & $65 \pm 22$ & $51 \pm 25$ & $80 \pm 29$ & $46 \pm 12$ \\
\hline
\end{tabular}

Significant difference $(\mathrm{P}<0.05)$ at the same time point: ${ }^{\mathrm{a} C o n j u g a t e ~ s i g n i f i c a n t l y ~ d i f f e r s ~ f r o m ~ N O D A G A ; ~}{ }^{\mathrm{b} C o n j u g a t e}$ significantly differs from DOTA; 'Conjugate significantly differs from DOTAGA.

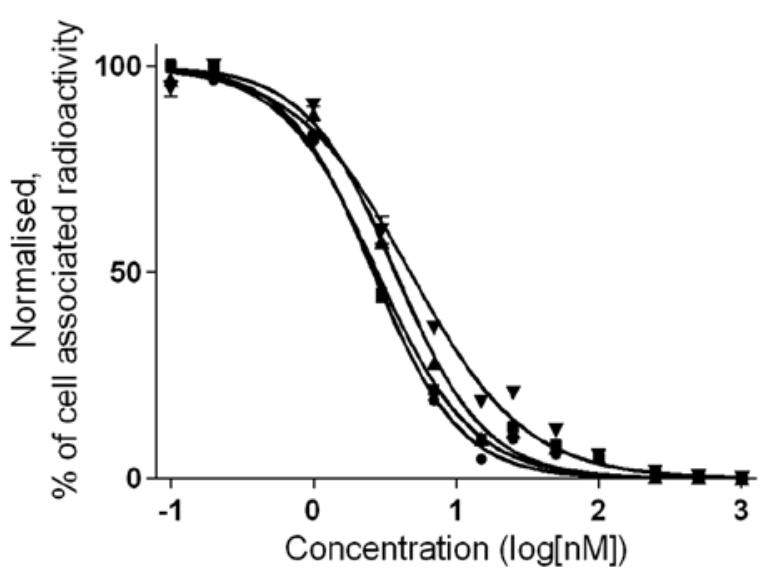

Figure 4. Inhibition of ${ }^{125} \mathrm{I}-\mathrm{Tyr} \mathrm{r}^{4}-\mathrm{BBN}$ binding to PC-3 cells with ${ }^{\text {nat } I n-X-\mathrm{PEG}_{2}-}$

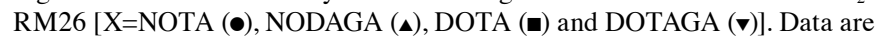
presented as the mean values of three dishes \pm SD.

${ }^{111}$ In-DOTAGA-PEG 2 -RM26. ${ }^{111}$ In-NOTA-PEG - RM26 showed the highest initial uptake and the slowest clearance of radioactivity from the liver. ${ }^{111}$ In-DOTA-PEG $2-\mathrm{RM}_{2} 6$ had a significantly lower retention of radioactivity in kidneys at both 4 and $24 \mathrm{~h}$ p.i. In addition, DOTA- and DOTAGA-conjugates had a significantly lower radioactivity concentration in muscle and bones than the other two variants at both time points. There was a clear chelator-dependent difference in the uptake of radioconjugates in receptor-positive organs (pancreas, stomach and small intestines) at $4 \mathrm{~h}$ p.i., when DOTA- and DOTAGA-containing variants showed a significantly lower uptake. At $4 \mathrm{~h}$ p.i., the pancreatic uptake of radioactivity was one order of magnitude higher for NOTA- and two orders higher for NODAGA-coupled analogs compared to DOTAand DOTAGA-containing variants.

Tumor-to-organ ratios are presented in Fig. 5 and Table IV. Remarkably, DOTA- and DOTAGA-coupled analogs provided significantly higher tumor-to-lung, tumor-to-pancreas, tumor-
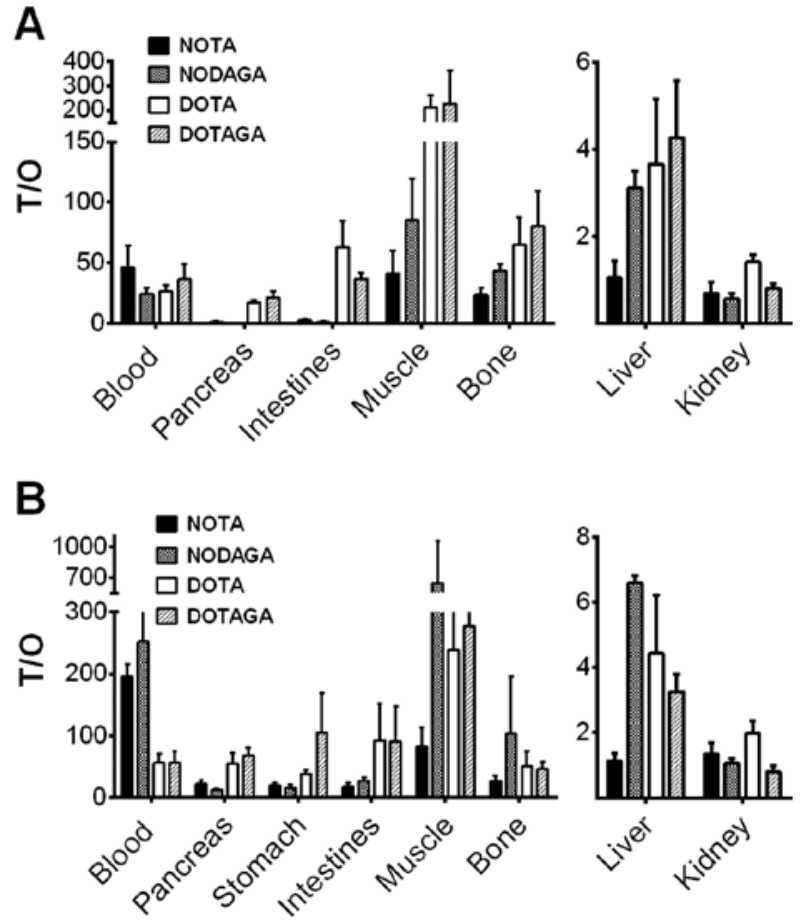

Figure 5. Tumor-to-normal-tissue ratios of ${ }^{111}$ In-X-PEG - RM26 (X=NOTA, NODAGA, DOTA and DOTAGA) in PC-3 xenografted BALB/C nu/nu mice at (A) $4 \mathrm{~h}$ and (B) $24 \mathrm{~h}$ p.i.

to-stomach, tumor-to-small intestines, tumor-to-muscle and tumor-to-bone ratios compared to NOTA- and NODAGAcontaining variants at $4 \mathrm{~h}$ p.i. The radioactivity accumulation in tumors at $4 \mathrm{~h}$ p.i. was exceeded only by kidney uptake in the case of ${ }^{111}$ In-DOTAGA-PEG $2-R M 26$, and it was higher than that in all normal organs, including excretory organs, for ${ }^{111}$ In-DOTA-PEG $2-\mathrm{RM} 26$. The $24 \mathrm{~h}$ p.i. tumor-to-organ ratios were $>1$ for all conjugates except for the tumor-to-kidney ratios for NOTA, NODAGA and DOTAGA conjugates and 


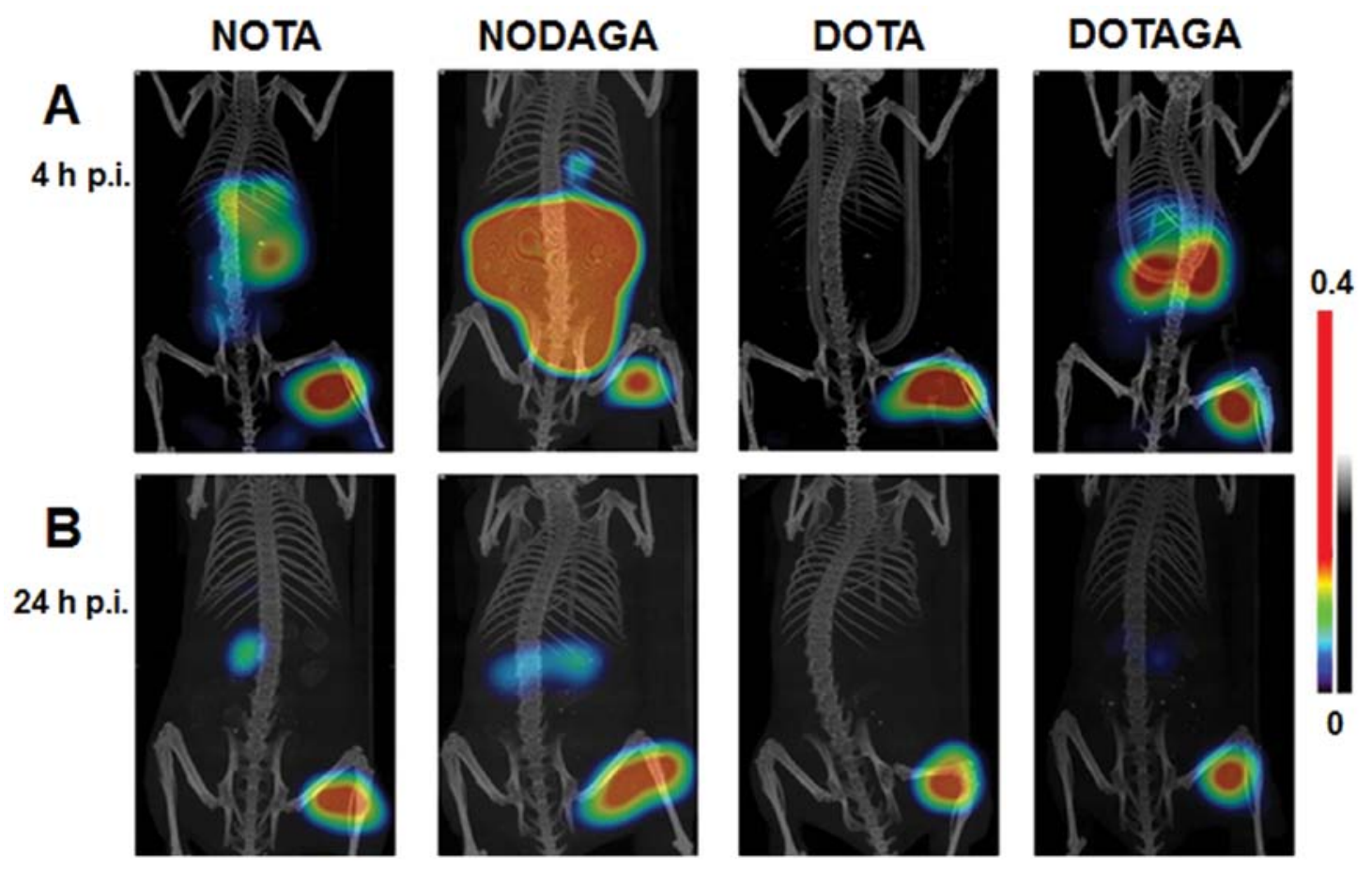

Figure 6. Coronal MIP images showing tracer distribution in PC-3 xenografted BALB/C nu/nu mice. The animals used for SPECT camera imaging were injected with 45 pmol of ${ }^{111}$ In-X-PEG - -RM26, (X=NOTA, NODAGA, DOTA and DOTAGA) (300 kBq) and euthanized at (A) $4 \mathrm{~h}$ and (B) $24 \mathrm{~h} \mathrm{p.i.}$

the tumor-to-liver ratio for NOTA conjugate. The washout of radioactivity from normal organs, including receptor-positive organs, was more rapid than from tumors. The NODAGA conjugate demonstrated the highest tumor-to-blood (significantly over DOTA and DOTAGA conjugates), tumor-to-muscle, and tumor-to-bone ratios at $24 \mathrm{~h}$ p.i. among the tested conjugates.

Imaging studies. Fig. 6 shows the coronal gamma camera scans acquired 4 and $24 \mathrm{~h}$ after the i.v. injection of ${ }^{111} \mathrm{In}-\mathrm{X}$ $\mathrm{PEG}_{2}-\mathrm{RM} 26$ (X=NOTA, NODAGA, DOTA, DOTAGA) into mice bearing PC-3 xenografts. The maximum intensity projection (MIP) images confirmed the capacity of all radioconjugates to clearly visualize GRPR expression. The higher uptake of NOTA and NODAGA at the earlier time point in receptor-positive organs in the abdomen can also be seen in the gamma camera images. The significantly higher tumor-tokidney ratios obtained at $4 \mathrm{~h}$ p.i. for ${ }^{111} \mathrm{In}-\mathrm{DOTA}-\mathrm{PEG}_{2}-\mathrm{RM} 26$ resulted in superior images, where only the tumor uptake was visualized. At $24 \mathrm{~h}$ p.i., signals from tumors in all studied conjugates dominated, while traces of radioactivity accumulation were visible in the kidneys for all conjugates except the DOTA-containing one.

\section{Discussion}

We have recently reported the influence of chelating moieties on the pharmacokinetic properties of ${ }^{68} \mathrm{Ga}$-labeled bombesin antagonist RM26 (D-Phe-Gln-Trp-Ala-Val-Gly-His-StaLeu- $\left.\mathrm{NH}_{2}\right)(13)$. The four constructs, which differed only in the chelating moieties $\left({ }^{68} \mathrm{Ga}-\mathrm{X}-\mathrm{PEG}_{2}-\mathrm{RM} 26, \mathrm{X}=\mathrm{NOTA}\right.$, NODAGA, DOTA, DOTAGA), showed significantly different biodistribution profiles, where ${ }^{68} \mathrm{Ga}-\mathrm{NOTA}-\mathrm{PEG}_{2}-\mathrm{RM} 26$ was the most promising agent for PET imaging in terms of tumor uptake, blood and whole body clearance, level of renal reabsorption of radioactivity, and tumor-to-nontumor ratios.

Despite the significant progress in the clinical application of PET during last decade, SPECT is still used for over $75 \%$ of all nuclear imaging procedures. Taking into account new developments in SPECT/CT, the number of established SPECT cameras and the low price of SPECT relative to PET, the development of SPECT tracers remains relevant. The abovementioned conjugates (X-PEG - -RM26, X=NOTA, NODAGA, DOTA, DOTAGA) could be easily labeled with indium-111, a three-valent radiometal suitable for SPECT. An additional advantage of ${ }^{111} \mathrm{In}$ is its longer half-life (2.8 days), which allows for imaging investigations at later time points (up to 2-3 days after administration). The investigations at later time points could potentially increase sensitivity due to the clearance of non-bound radioactivity from blood and healthy tissues. For prostate cancer, the detection of low abdominal lymph node involvement, when the enlargement could not be detected by CT or magnetic resonance tomography (MRT), is an ultimate goal for nuclear imaging. It was demonstrated that for secure SPECT detection of lesions with a diameter of $8 \mathrm{~mm}$, an effective uptake ratio of 84 is required (20).

At the same time, it is known that changing the radiometal could dramatically influence the affinity and biodistribution profile, leading to altered imaging properties even when radiometals have the same valency (21). $\mathrm{Ga}^{3+}$-DOTATOC had a 5-fold higher affinity to somatostatin receptor type 2 (SSTR2) and a 2-fold higher tumor uptake compared to $\mathrm{Y}^{3+}$-DOTATOC (22). These pronounced differences were attributed to the different coordination geometries of $\mathrm{Ga}^{3+}$ and $\mathrm{Y}^{3+}$ with DOTA, which resulted in conformational differences in the D-Phe 1 residue (23). Indium-111 has an identical oxidation state (+III) as the previously studied gallium- 68 but is different 
in size, having a larger ionic radius $(0.92 \AA)$ compared to that of gallium $(0.65 \AA)$. The coordination numbers of these metals are also different. Gallium is hexacoordinated to DOTA, the chelator adopting a pseudo-octahedral cis geometry with one free carboxylate group deprotonated at physiological $\mathrm{pH}$, whereas indium is octacoordinated to DOTA, exhibiting, in this case, a somewhat distorted square-antiprismatic geometry $(16,22)$. Both $\mathrm{Ga}^{\mathrm{III}}$ and $\mathrm{In}^{\mathrm{III}}$ are hexacoordinated to NOTA, forming trigonal prisms (24). However, indium-NOTA complexes have a noticeably distorted geometry (25). Some structural data for $\mathrm{Ga}^{\mathrm{III}}$ and $\mathrm{In}^{\mathrm{III}}$ complexes with NODAGA and DOTAGA can be drawn from the aforementioned parent NOTA and DOTA chelators. Taking the above in consideration, the imaging properties of the indium-111 labeled anti-GRPR antagonistic analog $\mathrm{PEG}_{2}-\mathrm{RM} 26$ coupled to different chelators should be re-evaluated.

All four compounds (X-PEG ${ }_{2}-\mathrm{RM} 26, \mathrm{X}=\mathrm{NOTA}$, NODAGA, DOTA, DOTAGA) (Fig. 1) were successfully radiolabeled with ${ }^{111} \mathrm{In}$, had almost identical quantitative yields and maintained in vitro binding specificity to GRPR-expressing PC-3 cells (Fig. 2). The cellular processing study confirmed the antagonistic properties of all conjugates, showing low internalization that reached $30 \%$ of cell-associated radioactivity after $24 \mathrm{~h}$. The similar internalization patterns indicated that chelators had no major effect on the cellular processing of analogs, although some differences could be observed. The NOTA-containing conjugate had the highest internalized radioactivity fraction and the NODAGA-containing conjugate demonstrated a decrease of cell-associated radioactivity between 8 and $24 \mathrm{~h}$ of incubation (Fig. 3). It is of interest that the NODAGA-containing conjugate demonstrated the best radioactivity retention in tumors, which lead to superior tumor-to-blood and tumor-to-muscle ratios at $24 \mathrm{~h}$ p.i.

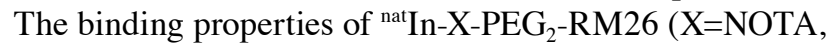
NODAGA, DOTA, DOTAGA) correlated with the net charge of radionuclide-chelator complexes, as shown by the competitive binding assay. While all $\mathrm{IC}_{50}$ values were in the low nanomolar range, the presence of a positive charge at the $\mathrm{N}$ terminus in the case of ${ }^{111}$ In-NOTA-PEG $2-\mathrm{RM}_{2} 6$ had a positive effect on binding affinity, while a negative charge ( ${ }^{111}$ In-DOTAGA-PEG 2 -RM26) resulted in lower affinity (Fig. 4 and Table II). These results are similar to those obtained for ${ }^{68} \mathrm{Ga}$-labeled conjugates and somatostatin analogs $(13,26,27)$. Ligand-receptor binding was also measured in real-time using LigandTracer instruments. The obtained $\mathrm{K}_{\mathrm{D}}$ values were in the subnanomolar range and had the same pattern as the $\mathrm{IC}_{50}$ values, confirming the favorable influence of an $\mathrm{N}$-terminus positive charge on the binding affinity of the peptides.

The biodistribution of ${ }^{111} \mathrm{In}-\mathrm{X}-\mathrm{PEG}_{2}-\mathrm{RM} 26$ (X=NOTA, NODAGA, DOTA, DOTAGA) in mice was characterized by a rapid clearance of radioactivity from the blood and non-GRPR-expressing organs (Table III). The excretion of radioactivity was predominantly via kidney ultrafiltration. Interestingly, the radioactivity uptake in the liver was significantly higher for ${ }^{111}$ In-NOTA-PEG 2 -RM26 with a positively charged metal complex compared to the other conjugates at both time points. Elevated liver uptake of lipophilic peptidebased radiopharmaceuticals is a known phenomenon (21) and was taken in account when we designed this imaging probe (9). Our rationale was that polyethylene glycol- containing linkers together with chelators should increase the local hydrophilicity of the probe (leading to decreased hepatic uptake), and, at the same time, not disturb the lipophilic part of the probe that is responsible for receptor recognition. This study endorsed this approach. It should also be noted that the conjugates containing NODAGA and DOTA that form neutral complexes with indium-111 had a two-fold lower liver uptake compared to the NOTA conjugate. Moreover, the liver uptake of the DOTAGA-containing variant that forms a negatively charged complex with indium-111 was 6-fold lower than the one seen for the positively charged NOTA conjugate. It should be mentioned that similar differences in affinities and liver uptake were found for gallium-labeled variants (13). Taken together, we can assume that, when increasing local hydrophilicity of the probe with the aim of decreasing hepatobiliary uptake, preference should be given to neutral moieties.

The uptake in receptor-positive organs (pancreas, stomach and small intestine) was significantly higher for the NOTA- and NODAGA-containing analogs. Notably, the uptake of radioactivity in the pancreas (the most abundantly GRPR-expressing organ), was ten-fold higher for ${ }^{111}$ In-NOTA-PEG $2-$ RM26 and 100-fold higher for ${ }^{111}$ In-NODAGA-PEG 2 -RM26 compared to DOTA- and DOTAGA-coupled variants at $4 \mathrm{~h}$ p.i. Nonetheless, tumor uptake of indium-111 labeled conjugates was nearly equal, correlating with their similar affinity values. We can speculate that the discrepancy between pancreatic and tumor uptake is due to interspecies differences between mouse and human GRPR. Maina et al reported a 13-fold difference between the binding affinities of radiolabeled bombesin analog Z-070 to human GRPR compared to mouse GRPR, whereas another bombesing analog Demobesin1 showed no difference in binding affinity to human and mouse GRPR (28). A similar uptake pattern with differences in the pancreas that did not match the tumor uptake in mice was also seen for other radiolabeled bombesin analogs $(29,30)$. However, the fourth extracellular domain of GRPR responsible for the binding of bombesin analogs was reported to be identical for humans and mice (31). In that case, the discrepancy between pancreatic and tumor uptake could reflect differences in off-target interactions due to different complex geometries. This could also explain the differences between the present study and the data published for gallium-68-labeled conjugates where a strong correlation between affinity and pancreatic and tumor uptake was found (13).

The higher initial uptake and slower clearance for ${ }^{111}$ In-NOTA-PEG 2 -RM26 in the liver is consistent with previous results, which indicated that the presence of a positive local charge at the $\mathrm{N}$ terminus of the peptide increases the hepatic uptake of radioactivity (21). Remarkably, the kidney retention of radioactivity was significantly lower for ${ }^{111}$ In-DOTA-PEG $2-$ RM26 compared to the other analogs. Overall, the tumor-to-organ ratios (except for the tumor-toblood ratio for the NOTA conjugate) were significantly higher in most organs for the conjugates containing tetraza chelators (DOTA and DOTAGA) at $4 \mathrm{~h}$ p.i. ${ }^{111} \mathrm{In}-\mathrm{DOTA}_{\mathrm{PEG}}-\mathrm{RM}_{2} 6$ had the best biodistribution properties at this time point (Table IV). The tumor uptake of radioactivity exceeded the uptake in anatomically relevant organs for prostate cancer (muscle, bone, intestine) and excretory organs (liver and kidneys). This was confirmed by microSPECT/CT images 
(Fig. 6). The higher uptake of radioactivity in the pancreas, stomach and small intestine for ${ }^{111}$ In-NODAGA-PEG $2-$ RM26 $_{2}$ and higher liver uptake for ${ }^{111}$ In-NOTA-PEG $2-$ RM$_{2} 6$ resulted in an increased abdominal background. The significantly higher tumor-to-kidney ratio resulted in the best imaging contrast for ${ }^{111}$ In-DOTA-PEG 2 -RM26 at $4 \mathrm{~h}$ p.i., when the only visualized structure was the tumor.

At later time points, despite the significant differences in tumor-to-nontumor ratios (see Fig. 5 and Table IV), all conjugates provided high contrast images of GRPR-expressing tumors due to efficient clearance of radioactivity from normal organs together with a significantly slower release from the tumors (Fig. 6). Nonetheless, taking into account the above-mentioned requirement of a high tumor-to-nontumor ratio for clear detection of small lesions (20), we should note that at the later time point of $24 \mathrm{~h}$ p.i., the NODAGA conjugate demonstrated the superior biodistribution profile, with the highest contrast to blood and anatomically relevant organs for prostate cancer, such as muscle and bones.

In conclusion, the radionuclide-chelator complex had a profound influence on the biodistribution and targeting properties of ${ }^{111}$ In-labeled bombesin antagonist RM26 to GRPR. The net charge of the radionuclide-chelator complex influenced the binding affinity and liver uptake of the radioconjugates. The geometry of the radionuclide-chelator complex appeared to have an even more profound effect on the biodistribution profile, accounting for the $4 \mathrm{~h}$ p.i. superiority of tetraza chelators for ${ }^{111}$ In-labeled radioconjugates. However, at $24 \mathrm{~h}$ p.i., ${ }^{111}$ In-NODAGA-PEG 2 -RM26 provided the best tumor-to-organ ratios for blood and organs that are anatomically relevant for prostate cancer, and it represents a suitable candidate for SPECT imaging of GRPR-expressing tumors.

\section{Acknowledgements}

This research was financially supported by grants from the Swedish Cancer Society (Cancerfonden) and the Swedish Research Council (Vetenskapsrådet).

\section{References}

1. Smith CJ, Volkert WA and Hoffman TJ: Gastrin releasing peptide (GRP) receptor targeted radiopharmaceuticals: A concise update. Nucl Med Biol 30: 861-868, 2003.

2. Thompson IM, Pauler DK, Goodman PJ, Tangen CM, Lucia MS, Parnes HL, Minasian LM, Ford LG, Lippman SM, Crawford ED, et al: Prevalence of prostate cancer among men with a prostatespecific antigen level $<$ or $=4.0 \mathrm{ng}$ per milliliter. N Engl J Med 350: 2239-2246, 2004.

3. Scardino PT, Weaver R and Hudson MA: Early detection of prostate cancer. Hum Pathol 23: 211-222, 1992.

4. Bubendorf L, Schöpfer A, Wagner U, Sauter G, Moch H, Willi N, Gasser TC and Mihatsch MJ: Metastatic patterns of prostate cancer: An autopsy study of 1,589 patients. Hum Pathol 31: $578-583,2000$

5. Zhang H, Abiraj K, Thorek DL, Waser B, Smith-Jones PM, Honer M, Reubi JC and Maecke HR: Evolution of bombesin conjugates for targeted PET imaging of tumors. PLoS One 7: e44046, 2012.

6. Bodei L, Paganelli G and Mariani G: Receptor radionuclide therapy of tumors: A road from basic research to clinical applications. J Nucl Med 47: 375-377, 2006.

7. Ginj M, Zhang H, Waser B, Cescato R, Wild D, Wang X, Erchegyi J, Rivier J, Mäcke HR and Reubi JC: Radiolabeled somatostatin receptor antagonists are preferable to agonists for in vivo peptide receptor targeting of tumors. Proc Natl Acad Sci USA 103: 16436-16441, 2006.
8. Cescato R, Maina T, Nock B, Nikolopoulou A, Charalambidis D, Piccand V and Reubi JC: Bombesin receptor antagonists may be preferable to agonists for tumor targeting. J Nucl Med 49: 318-326, 2008.

9. Varasteh Z, Velikyan I, Lindeberg G, Sörensen J, Larhed M, Sandström M, Selvaraju RK, Malmberg J, Tolmachev V and Orlova A: Synthesis and characterization of a high-affinity NOTA-conjugated bombesin antagonist for GRPR-targeted tumor imaging. Bioconjug Chem 24: 1144-1153, 2013.

10. Varasteh Z, Aberg O, Velikyan I, Lindeberg G, Sörensen J, Larhed M, Antoni G, Sandström M, Tolmachev V and Orlova A: In vitro and in vivo evaluation of a (18)F-labeled high affinity NOTA conjugated bombesin antagonist as a PET ligand for GRPR-targeted tumor imaging. PLoS One 8: e81932, 2013.

11. Varshney R, Hazari PP, Fernandez P, Schulz J, Allard M and Mishra AK: 68Ga-labeled bombesin analogs for receptormediated imaging. In: Theranostics, Gallium-68, and Other Radionuclides: A Pathway to Personalized Diagnosis and Treatment. Baum RP and Rösch F (eds). Springer, Heidelberg, New York, Dordrecht, London, pp221-256, 2013.

12. Varasteh Z, Rosenström U, Velikyan I, Mitran B, Altai M, Honarvar H, Rosestedt M, Lindeberg G, Sörensen J, Larhed M, et al: The effect of mini-PEG-based spacer length on binding and pharmacokinetic properties of a 68Ga-labeled NOTA-conjugated antagonistic analog of bombesin. Molecules 19: 10455-10472, 2014.

13. Varasteh Z, Mitran B, Rosenström U, Velikyan I, Rosestedt M, Lindeberg G, Sörensen J, Larhed M, Tolmachev V and Orlova A: The effect of macrocyclic chelators on the targeting properties of the $68 \mathrm{Ga}$-labeled gastrin releasing peptide receptor antagonist PEG2-RM26. Nucl Med Biol 42: 446-454, 2015.

14. Müller C and Schibli R: Single photon emission computed tomography tracer. In: Molecular Imaging in Oncology. Schober O and Riemann B (eds). Springer, Heidelberg, New York, Dordrecht, London, pp65-105, 2013.

15. Ginj M and Maecke HR: Radiometallo-labeled peptides in tumor diagnosis and therapy. In: Metal Ions in Biological Systems: Metal Complexes in Tumor Diagnosis and as Anticancer Agents. Sigel A and Sigel H (eds). Vol. 42. FontisMedia S.A. and Marcel Dekker, Inc., pp109-142, 2004.

16. Heppeler A, André JP, Buschmann I, Wang X, Reubi JC, Hennig M, Kaden TA and Maecke HR: Metal-ion-dependent biological properties of a chelator-derived somatostatin analogue for tumour targeting. Chemistry 14: 3026-3034, 2008.

17. Bartholomä MD, Louie AS, Valliant JF and Zubieta J: Technetium and gallium derived radiopharmaceuticals: Comparing and contrasting the chemistry of two important radiometals for the molecular imaging era. Chem Rev 110: 2903-2920, 2010.

18. Lozza C, Navarro-Teulon I, Pèlegrin A, Pouget JP and Vivès E: Peptides in receptor-mediated radiotherapy: From design to the clinical application in cancers. Front Oncol 3: 247, 2013.

19. Xu B, Varasteh Z, Orlova A, Andersson K, Larhammar D and Björkelund $\mathrm{H}$ : Detecting ligand interactions with $\mathrm{G}$ proteincoupled receptors in real-time on living cells. Biochem Biophys Res Commun 441: 820-824, 2013.

20. Eckelman WC, Kilbourn MR and Mathis CA: Specific to nonspecific binding in radiopharmaceutical studies: It's not so simple as it seems! Nucl Med Biol 36: 235-237, 2009.

21. Tolmachev V and Orlova A: Influence of labelling methods on biodistribution and imaging properties of radiolabelled peptides for visualisation of molecular therapeutic targets. Curr Med Chem 17: 2636-2655, 2010.

22. Heppeler A, Froidevaux S, Macke HR, Jermann E, Behe M, Powell $\mathrm{P}$ and Hennig M: Radiometal-labelled macrocyclic chelator-derivatised somatostatin analogue with superb tumour targeting properties and potential for receptor rmediated internal radiotherapy. Chemistry 5: 1974-1981, 1999.

23. Deshmukh MV, Voll G, Kühlewein A, Mäcke H, Schmitt J, Kessler H and Gemmecker G: NMR studies reveal structural differences between the gallium and yttrium complexes of DOTA-D-Phe1-Tyr3-octreotide. J Med Chem 48: 1506-1514, 2005.

24. Broan CJ, Cox JPL, Craig AS, Kataky R, Parker D, Harrison A, Randall A and Ferguson GJ: Structure and solution stability of indium and gallium complexes of 1,4,7-triazacyclononanetriacetate and of yttrium complexes of 1,4,7,10-tetraazacyclododecanetetraacetate and related ligands: Kinetically stable complexes for use in imaging and radioimmunotherapy. X-Ray molecular structure of the indium and gallium complexes of 1,4,7-triazacyclononane1,4,7-triacetic acid. J Chem Soc Perkin Trans 2: 87-99, 1991. 
25. Matthews RC, Parker D, Ferguson G, Kaitner B, Harisson A and Royle L: Synthesis and structure of stable indium and gallium complexes of (R)-1,4,7-tris(2'-methylcarboxymethyl)triazacyclononane. Polyhedron 10: 1951-1953, 1991.

26. Abiraj K, Mansi R, Tamma ML, Fani M, Forrer F, Nicolas G, Cescato R, Reubi JC and Maecke HR: Bombesin antagonistbased radioligands for translational nuclear imaging of gastrin-releasing peptide receptor-positive tumors. J Nucl Med 52: 1970-1978, 2011.

27. Gourni E, Mansi R, Jamous M, Waser B, Smerling C, Burian A, Buchegger F, Reubi JC and Maecke HR: N-terminal modifications improve the receptor affinity and pharmacokinetics of radiolabeled peptidic gastrin-releasing peptide receptor antagonists: Examples of $68 \mathrm{Ga}$ - and $64 \mathrm{Cu}$-labeled peptides for PET imaging. J Nucl Med 55: 1719-1725, 2014.

28. Maina T, Nock BA, Zhang H, Nikolopoulou A, Waser B, Reubi JC and Maecke HR: Species differences of bombesin analog interactions with GRP-R define the choice of animal models in the development of GRP-R-targeting drugs. J Nucl Med 46: 823-830, 2005 .
29. Fournier P, Dumulon-Perreault V, Ait-Mohand S, Tremblay S, Bénard F, Lecomte R and Guérin B: Novel radiolabeled peptides for breast and prostate tumor PET imaging: (64) Cu/and (68) Ga/NOTA-PEG-[D-Tyr(6),,3Ala(11),Thi(13),Nle(14)]BBN(6-14). Bioconjug Chem 23: 1687-1693, 2012.

30. Lane SR, Nanda P, Rold TL, Sieckman GL, Figueroa SD, Hoffman TJ, Jurisson SS and Smith CJ: Optimization, biological evaluation and microPET imaging of copper-64-labeled bombesin agonists, [64Cu-NO2A-(X)-BBN(7-14)NH2], in a prostate tumor xenografted mouse model. Nucl Med Biol 37: 751-761, 2010.

31. Tokita K, Katsuno T, Hocart SJ, Coy DH, Llinares M, Martinez J and Jensen RT: Molecular basis for selectivity of high affinity peptide antagonists for the gastrin-releasing peptide receptor. J Biol Chem 276: 36652-36663, 2001. 